\title{
An Investment Decision Making Methodology Based On Type-2 Fuzzy Ahp: A Case Study on Borsa Istanbul (Bist)
}

\author{
Beyza Ahlatcioglu Ozkok ${ }^{1, *}$ and Hale Gonce Kocken ${ }^{2}$ \\ ${ }^{1}$ Department of Mathematics, Yildiz Technical University, Istanbul, Turkey \\ ${ }^{2}$ Department of Mathematical Engineering, Yildiz Technical University, Istanbul, Turkey \\ *Corresponding author
}

\begin{abstract}
Evaluation of investment alternatives, taking effective and efficient investment decisions are one of the most important problems of our lives. Portfolio selection problem, can be described as one of the decision-making problem that is to decide which stocks are to be chosen for investment and in what proportions they will be bought. Analytical hierarchy process (AHP) is one of the very well-known multi criteria decision making techniques. Lately many extensions are proposed for AHP in order to handle fuzziness of real life problems by researchers. The most novel extension is to use interval type 2 fuzzy numbers for evaluation matrices in fuzzy AHP. In this study, we worked on portfolio selection problem and used type 2 fuzzy AHP in order to solve the problem and provided a case study on Borsa Istanbul (BIST).
\end{abstract}

Keywords: portfolio selection problem, investment decision; fuzzy analytical hierarchy process; type-2 fuzzy numbers; fuzzy decision making.

\section{Introduction}

The portfolio selection problem has been one of the most important issues in modern finance since the 1950s. In the literature, there are several approaches to constructing a portfolio. Historically, the mean-variance model is the first example of a portfolio optimization problem, and it is credited to Markowitz, who presented his ideas in (Markowitz, 1952). This model is important because mean-variance analysis provides a basis for the derivation of the equilibrium model known variously as the Capital Asset Pricing Model (CAPM), Sharpe-Lintner model, black model and two-factor model (Alexander, et al., 2003, Tiryaki and Ahlatcioglu, 2009).

Here we summarized some of the important mathematical models which are proposed for the portfolio selection problem. In (Tanaka \& Guo, 1999), portfolio selection models are formulated by quadratic programming, based on two kinds of possibility distributions. A model using genetic algorithms for portfolio selection is proposed in (Xia et al., 2000). Two portfolio selection models based on fuzzy probabilities and possibility distributions are proposed in (Tanaka et al., 2000). (Inuiguchi and Tanino, 2000) proposed a new possibilistic programming approach based on the worst regret to the portfolio selection, considering how a model yields a distributive investment solution. (Parra et al., 2001) formulated a fuzzy goal programming with fuzzy goals and fuzzy constraints, taking into account three criteria: return, risk and liquidity. (Ong et al., 2005) proposed a method that incorporates the grey and possibilistic regression models in formulating a novel portfolio selection model. In their paper (Tiryaki and Ahlatcioglu, 2005) proposed a new ranking and weighting method and applied it to the selection 
of stocks on the ISE. In (Lacagnina and Pecorella, 2006), they developed a multistage stochastic fuzzy program with soft constraints and recourse in order to capture both uncertainty and imprecision and used their program to solve a portfolio management problem. In (Huang et al., 2006), the conventional mean-variance method is revised to determine the optimal portfolio selection under the uncertain situation. Using Sharpe's single-index model in a soft framework, (Terol et al., 2006) formulated a Fuzzy Compromise Programming problem in order to solve portfolio selection problems. (Giove et al., 2006) considered a portfolio selection problem in which the prices of the securities are treated as interval variables. In (Zhang et al., 2007) two kinds of portfolio selection models based on lower and upper possibilistic means and possibilistic variance and presented an algorithm which can derive the possibilistic efficient frontier of the problem are proposed. In (Tiryaki and Ahlatcioglu, 2009), they combined the fuzzy AHP with the portfolio selection problem. In order to measure the asymmetry of fuzzy portfolio return, a concept of skewness is defined as the third central moment in (Li et al., 2010), and its mathematical properties are studied. In (Bhattacharyya et al., 2011), they utilized the concept of interval numbers in fuzzy set theory to extend the classical mean-variance portfolio selection model into mean-variance-skewness model with consideration of transaction cost. Based on the membership function, (Li et al., 2015) redefined the concepts of mean and variance for fuzzy numbers, also proposed the concept of distortion, and formulated a fuzzy mean-variance-skewness portfolio selection model. They studied stock portfolio selection problem based on varying conservative-neutral-aggressive attitudes in (Zhou et al, 2018). In their paper, the return rates of stocks are characterized by fuzzy variables. The Paretooptimal solutions are obtained by maximizing the return and minimizing the risk subject to constraints of transaction cost and value at risk.

AHP is widely used for multi-criteria decision making and has successfully been applied to many practical problems (Saaty, 1980). Traditional AHP requires exact or crisp judgements (numbers). However, due to the complexity and uncertainty involved in real world decision problems, decision makers might be more reluctant to provide crisp judgements than fuzzy ones. Furthermore, even when people use the same words, individual judgments of events are invariably subjective, and the interpretations that they attach to the same words may differ. Moreover, even if the meaning of a word is well-defined (e.g., the linguistic comparison labels in the standard AHP questionnaire responses), the boundary criterion that determines whether an object does or does not belong to the set defined by that word is often fuzzy or vague. This is why fuzzy numbers and fuzzy sets have been introduced to characterize linguistic variables. A linguistic variable is a variable whose values are not numbers but words or sentences from a natural or artificial language. Linguistic variables are used to represent the imprecise nature of human cognition when we try to translate people's opinions into spatial data. The preferences in AHP are essentially human judgments based on human perceptions (this is especially true for intangibles), so fuzzy approaches allow for a more accurate description of the decisionmaking process (Chen et al., 2008; Tiryaki and Ahlatcioglu, 2009). In the literature, several approaches to fuzzy AHP have been proposed by various authors. The first method of fuzzy AHP proposed by (Van Laarhoven and Pedrycz, 1983). In this method, elements in the reciprocal matrix were expressed by triangular fuzzy numbers. In contrast, (Buckley, 1985) used trapezoidal numbers to determine fuzzy comparison ratios. He criticized Laarhoven and Pedrycz's method since linear equations do not always yield a unique solution, and this method is only valid for triangular fuzzy numbers. In (Boender et al., 1989), they pointed out an error in the method of Laarhoven and Pedrycz, and showed how it can be corrected. (Chang, 1996) proposed a method that uses triangular fuzzy numbers for the pairwise comparison scale of fuzzy AHP and extent analysis for the synthetic extent values of pairwise comparisons. 
In type-1 fuzzy sets, each element has a degree of membership which is described with a membership function valued in the interval $[0,1]$. The concept of a type-2 fuzzy set was introduced by (Zadeh, 1965) as an extension of the concept of an ordinary fuzzy set called a type-1 fuzzy set. While the membership functions of type- 1 fuzzy sets are two-dimensional, the membership functions of type- 2 fuzzy sets are three-dimensional. It is the new third-dimension that provides additional degrees of freedom that make it possible to directly model uncertainties (Kahraman et al., 2014). In (Kahraman et al., 2014), they developed an interval type-2 fuzzy AHP method and presented into the literature for the first time. The linguistic scale of fuzzy AHP is expressed in a more detailed and flexible way by interval type-2 fuzzy sets. New defuzzification methods for both triangular and trapezoidal type-2 fuzzy sets are also incorporated into their developed method. In this study, we worked on portfolio selection problem and used interval type 2 fuzzy AHP method which is proposed by (Kahraman et al., 2014) in order to solve the problem and provided a case study on Borsa Istanbul (BIST).

\section{Interval type-2 fuzzy sets}

In this section, brief information about interval type-2 fuzzy sets is presented (Kahraman et al., 2014).

Definition 1: A type-2 fuzzy set $\tilde{\tilde{A}}$ in the universe of discourse $X$ can be represented by a type-2 membership function $\mu_{\tilde{\tilde{A}}}(x)$, shown as follows:

$$
\tilde{\tilde{A}}=\left\{\left((x, u), \mu_{\tilde{\tilde{A}}}(x, u)\right)|\forall x \in X,| \forall u \in J_{x} \subseteq[0,1], 0 \leq \mu_{\tilde{\tilde{A}}}(x, u) \leq 1\right\}
$$

where $J_{x} \in[0,1]$ denotes an interval $[0,1]$. The type-2 fuzzy set $\tilde{\tilde{A}}$ also can be represented as follows:

$$
\tilde{\tilde{A}}=\int_{x \in X} \int_{u \in J_{x}} \mu_{\tilde{\tilde{A}}}(x, u) /(x, u)
$$

where $J_{x} \subseteq[0,1]$ and $\iint$ denotes union over all admissible $x$ and $u$.

Definition 2: The upper and lower membership functions of an interval type-2 fuzzy set are type-1 membership functions. A trapezoidal interval type-2 fuzzy set is illustrated as $\tilde{\tilde{A}}_{i}=\left(\tilde{A}_{i}^{U} ; \tilde{A}_{i}^{L}\right)=\left(\left(a_{i 1}^{U}, a_{i 2}^{U}, a_{i 3}^{U}, a_{i 4}^{U} ; H_{1}\left(\tilde{A}_{i}^{U}\right), H_{2}\left(\tilde{A}_{i}^{U}\right)\right),\left(a_{i 1}^{L}, a_{i 2}^{L}, a_{i 3}^{L}, a_{i 4}^{L} ; H_{1}\left(\tilde{A}_{i}^{L}\right), H_{2}\left(\tilde{A}_{i}^{L}\right)\right)\right)$ where $\tilde{A}_{i}^{U}$ and $\tilde{A}_{i}^{L}$ are type-1 fuzzy sets, $a_{i 1}^{U}, a_{i 2}^{U}, a_{i 3}^{U}, a_{i 4}^{U}, a_{i 1}^{L}, a_{i 2}^{L}, a_{i 3}^{L}$ and $a_{i 4}^{L}$ are the reference points of the interval type-2 fuzzy set $\tilde{\tilde{A}}_{i}, H_{j}\left(\tilde{A}_{i}^{U}\right)$; denotes the membership value of the element $a_{i(j+1)}^{U}$ in the upper trapezoidal membership function $\tilde{A}_{i}^{U}, 1 \leq j \leq 2, H_{j}\left(\tilde{A}_{i}^{L}\right) ; 1 \leq j \leq 2$ denotes the membership value of the element $a_{i(j+1)}^{L}$ in the lower trapezoidal membership function $\tilde{A}_{i}^{L}$, $1 \leq j \leq 2, H_{1}\left(\tilde{A}_{i}^{U}\right) \in[0,1], H_{2}\left(\tilde{A}_{i}^{U}\right) \in[0,1], H_{1}\left(\tilde{A}_{i}^{L}\right) \in[0,1], H_{2}\left(\tilde{A}_{i}^{L}\right) \in[0,1]$ ve $1 \leq i \leq n$. 


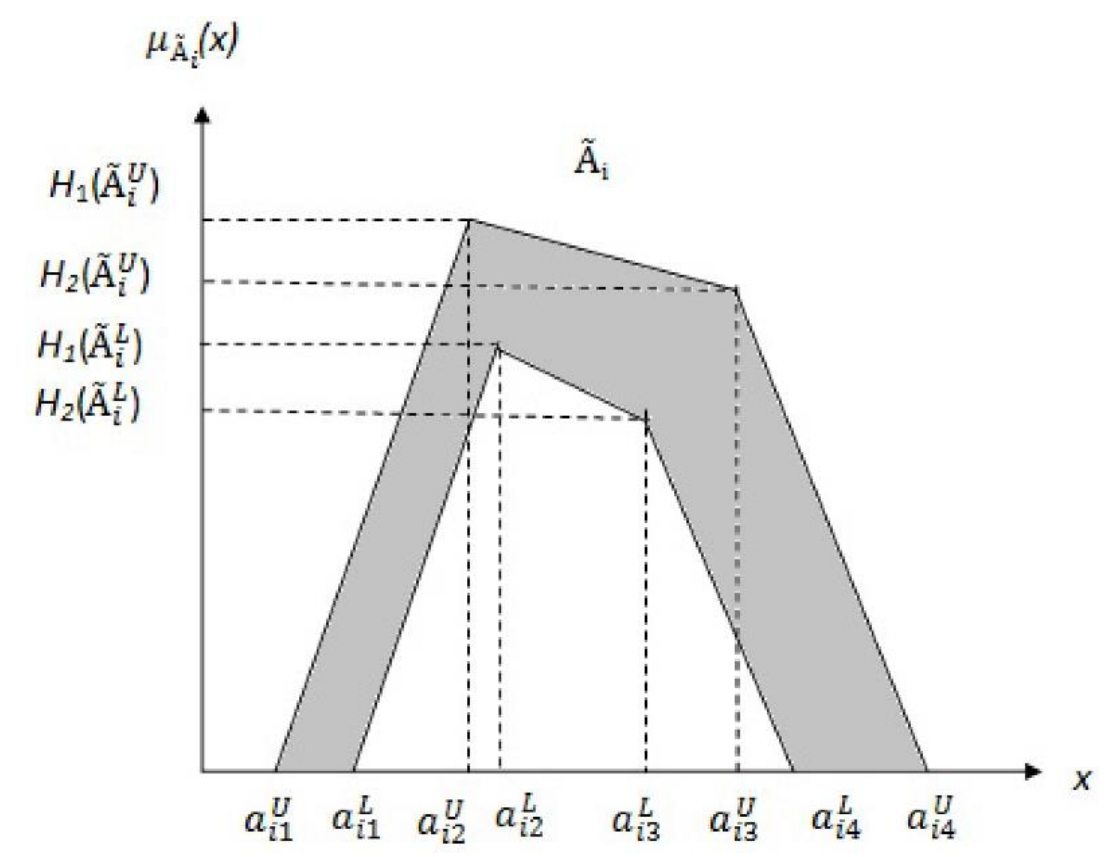

Source: (Kahraman et al., 2014).

Let $\quad \tilde{\tilde{A}}_{1}=\left(\tilde{A}_{1}^{U} ; \tilde{A}_{1}^{L}\right)=\left(\left(a_{11}^{U}, a_{12}^{U}, a_{13}^{U}, a_{14}^{U} ; H_{1}\left(\tilde{A}_{1}^{U}\right), H_{2}\left(\tilde{A}_{1}^{U}\right)\right),\left(a_{11}^{L}, a_{12}^{L}, a_{13}^{L}, a_{14}^{L} ; H_{1}\left(\tilde{A}_{1}^{L}\right), H_{2}\left(\tilde{A}_{1}^{L}\right)\right)\right)$ and $\tilde{\tilde{A}}_{2}=\left(\tilde{A}_{2}^{U} ; \tilde{A}_{2}^{L}\right)=\left(\left(a_{21}^{U}, a_{22}^{U}, a_{23}^{U}, a_{24}^{U} ; H_{1}\left(\tilde{A}_{2}^{U}\right), H_{2}\left(\tilde{A}_{2}^{U}\right)\right),\left(a_{21}^{L}, a_{22}^{L}, a_{23}^{L}, a_{24}^{L} ; H_{1}\left(\tilde{A}_{2}^{L}\right), H_{2}\left(\tilde{A}_{2}^{L}\right)\right)\right)$. be trapezoidal interval type-2 fuzzy sets.

Definition 3: The addition operation between $\tilde{\tilde{A}}_{1}$ and $\tilde{\tilde{A}}_{2}$ is defined as follows:

$\tilde{\tilde{A}}_{1} \oplus \tilde{\tilde{A}}_{2}=\left(a_{11}^{U}+a_{21}^{U}, a_{12}^{U}+a_{22}^{U}, a_{13}^{U}+a_{23}^{U}, a_{14}^{U}+a_{24}^{U} ; \min \left(H_{1}\left(\tilde{A}_{1}^{U}\right), H_{1}\left(\tilde{A}_{2}^{U}\right)\right), \min \left(H_{1}\left(\tilde{A}_{1}^{U}\right), H_{1}\left(\tilde{A}_{2}^{U}\right)\right)\right)$, $\left(a_{11}^{L}+a_{21}^{L}, a_{12}^{L}+a_{22}^{L}, a_{13}^{L}+a_{23}^{L}, a_{14}^{L}+a_{24}^{L} ; \min \left(H_{1}\left(\tilde{A}_{1}^{L}\right), H_{1}\left(\tilde{A}_{2}^{L}\right)\right), \min \left(H_{1}\left(\tilde{A}_{1}^{L}\right), H_{1}\left(\tilde{A}_{2}^{L}\right)\right)\right)$.

Definition 4: The subtraction operation between $\tilde{\tilde{A}}_{1}$ and $\tilde{\tilde{A}}_{2}$ is defined as follows: $\tilde{\tilde{A}}_{1} \Theta \tilde{\tilde{A}}_{2}=\left(a_{11}^{U}-a_{24}^{U}, a_{12}^{U}-a_{23}^{U}, a_{13}^{U}-a_{22}^{U}, a_{14}^{U}-a_{21}^{U} ; \min \left(H_{1}\left(\tilde{A}_{1}^{U}\right), H_{1}\left(\tilde{A}_{2}^{U}\right)\right), \min \left(H_{1}\left(\tilde{A}_{1}^{U}\right), H_{1}\left(\tilde{A}_{2}^{U}\right)\right)\right)$, $\left(a_{11}^{L}-a_{24}^{L}, a_{12}^{L}-a_{23}^{L}, a_{13}^{L}-a_{22}^{L}, a_{14}^{L}-a_{21}^{L} ; \min \left(H_{1}\left(\tilde{A}_{1}^{L}\right), H_{1}\left(\tilde{A}_{2}^{L}\right)\right), \min \left(H_{1}\left(\tilde{A}_{1}^{L}\right), H_{1}\left(\tilde{A}_{2}^{L}\right)\right)\right)$.

Definition 5: The multiplication operation between $\tilde{\tilde{A}}_{1}$ and $\tilde{\tilde{A}}_{2}$ is defined as follows:

$\tilde{\tilde{A}}_{1} \otimes \tilde{A}_{2} \cong\left(a_{11}^{U} \otimes a_{21}^{U}, a_{12}^{U} \otimes a_{22}^{U}, a_{13}^{U} \otimes a_{23}^{U}, a_{14}^{U} \otimes a_{24}^{U} ; \min \left(H_{1}\left(\tilde{A}_{1}^{U}\right), H_{1}\left(\tilde{A}_{2}^{U}\right)\right), \min \left(H_{1}\left(\tilde{A}_{1}^{U}\right), H_{1}\left(\tilde{A}_{2}^{U}\right)\right)\right)$ $\left(a_{11}^{L} \otimes a_{21}^{L}, a_{12}^{L} \otimes a_{22}^{L}, a_{13}^{L} \otimes a_{23}^{L}, a_{14}^{L} \otimes a_{24}^{L} ; \min \left(H_{1}\left(\tilde{A}_{1}^{L}\right), H_{1}\left(\tilde{A}_{2}^{L}\right)\right), \min \left(H_{1}\left(\tilde{A}_{1}^{L}\right), H_{1}\left(\tilde{A}_{2}^{L}\right)\right)\right)$.

Definition 6: The arithmetic operations between the trapezoidal interval type-2 fuzzy set $\tilde{\tilde{A}}_{1}$ and a scalar $k>0$ can be given as:

$$
k \tilde{\tilde{A}}_{1}=\left(\left(k a_{11}^{U}, k a_{12}^{U}, k a_{13}^{U}, k a_{14}^{U} ; H_{1}\left(\tilde{A}_{1}^{U}\right), H_{2}\left(\tilde{A}_{1}^{U}\right)\right),\left(k a_{11}^{L}, k a_{12}^{L}, k a_{13}^{L}, k a_{14}^{L} ; H_{1}\left(\tilde{A}_{1}^{L}\right), H_{2}\left(\tilde{A}_{1}^{L}\right)\right)\right)
$$




$$
\frac{\tilde{\tilde{A}}_{1}}{k}=\left(\left(\frac{a_{11}^{U}}{k}, \frac{a_{12}^{U}}{k}, \frac{a_{13}^{U}}{k}, \frac{a_{14}^{U}}{k} ; H_{1}\left(\tilde{A}_{1}^{U}\right), H_{2}\left(\tilde{A}_{1}^{U}\right)\right),\left(\frac{a_{11}^{L}}{k}, \frac{a_{12}^{L}}{k}, \frac{a_{13}^{L}}{k}, \frac{a_{14}^{L}}{k} ; H_{1}\left(\tilde{A}_{1}^{L}\right), H_{2}\left(\tilde{A}_{1}^{L}\right)\right) .\right.
$$

Definition 7: The reciprocal of the trapezoidal interval type-2 fuzzy set $\tilde{\tilde{A}}_{1}$ is defined as follows:

$$
\frac{1}{\tilde{\tilde{A}}_{1}}=\left(\tilde{\tilde{A}}_{1}\right)^{-1}=\left(\left(\frac{1}{a_{14}^{U}}, \frac{1}{a_{13}^{U}}, \frac{1}{a_{12}^{U}}, \frac{1}{a_{11}^{U}} ; H_{1}\left(\tilde{A}_{1}^{U}\right), H_{2}\left(\tilde{A}_{1}^{U}\right)\right),\left(\frac{1}{a_{14}^{L}}, \frac{1}{a_{13}^{L}}, \frac{1}{a_{12}^{L}}, \frac{1}{a_{11}^{L}} ; H_{1}\left(\tilde{A}_{1}^{L}\right), H_{2}\left(\tilde{A}_{1}^{L}\right)\right)\right) \text {. }
$$

Definition 8: In (Kahraman et al., 2014) the defuzzified value $\operatorname{DTraT}\left(\tilde{\tilde{A}}_{1}\right)$ of a trapezoidal type2 fuzzy set $\tilde{\tilde{A}}_{1}$ is given as follows:

$$
\operatorname{DTraT}\left(\tilde{\tilde{A}}_{1}\right)=\frac{\frac{\alpha}{4}+a_{11}^{U}+\frac{\beta}{4}+a_{11}^{L}}{2}
$$

where

$$
\alpha=\left(a_{14}^{U}-a_{11}^{U}\right)+\left(H_{1}\left(\tilde{A}_{1}^{U}\right) a_{12}^{U}-a_{11}^{U}\right)+\left(H_{2}\left(\tilde{A}_{1}^{U}\right) a_{13}^{U}-a_{11}^{U}\right)
$$

and

$\beta=\left(a_{14}^{L}-a_{11}^{L}\right)+\left(H_{1}\left(\tilde{A}_{1}^{L}\right) a_{12}^{L}-a_{11}^{L}\right)+\left(H_{2}\left(\tilde{A}_{1}^{L}\right) a_{13}^{L}-a_{11}^{L}\right)$.

After obtaining the defuzzied values, trapezoidal interval type-2 fuzzy sets can be ranked with respect to these values.

\section{Type-2 fuzzy AHP}

In this section, type-2 fuzzy AHP method which is proposed in (Kahraman et al., 2014) is explained as follows:

Step 1. Fuzzy pairwise comparison matrices among all the criteria in the dimensions of the hierarchy system are constructed. The result of the comparisons is constructed as fuzzy pairwise comparison matrices as following:

$$
\tilde{\tilde{A}}=\left[\begin{array}{cccc}
1 & \tilde{\tilde{a}}_{12} & \cdots & \tilde{\tilde{a}}_{1 n} \\
\tilde{\tilde{a}}_{21} & 1 & \cdots & \tilde{\tilde{a}}_{2 n} \\
\vdots & \vdots & \ddots & \vdots \\
\tilde{\tilde{a}}_{n 1} & \tilde{\tilde{a}}_{n 2} & \cdots & 1
\end{array}\right]=\left[\begin{array}{cccc}
1 & \tilde{\tilde{a}}_{12} & \cdots & \tilde{\tilde{a}}_{1 n} \\
1 / \tilde{\tilde{a}}_{12} & 1 & \cdots & \tilde{\tilde{a}}_{2 n} \\
\vdots & \vdots & \ddots & \vdots \\
1 / \tilde{\tilde{a}}_{1 n} & 1 / \tilde{\tilde{a}}_{2 n} & \cdots & 1
\end{array}\right]
$$

The linguistic variables and their trapezoidal interval type- 2 fuzzy scales which can be used in interval type- 2 fuzzy AHP are given in Table 1.

Table 1: The definition and interval type 2 fuzzy scales of the linguistic variables.

\begin{tabular}{|l|c|}
\hline \multicolumn{1}{|c|}{ Linguistic variables } & Trapezoidal interval type-2 fuzzy scales \\
\hline Absolutely Strong (AS) & $(7,8,9,9 ; 1,1)(7.2,8.2,8.8,9 ; 0.8,0.8)$ \\
\hline Very Strong (VS) & $(5,6,8,9 ; 1,1)(5.2,6.2,7.8,8.8 ; 0.8,0.8)$ \\
\hline Fairly Strong (FS) & $(3,4,6,7 ; 1,1)(3.2,4.2,5.8,6.8 ; 0.8,0.8)$ \\
\hline Slightly Strong (SS) & $(1,2,4,5 ; 1,1)(1.2,2.2,3.8,4.8 ; 0.8,0.8)$ \\
\hline Exactly Equal (E) & $(1,1,1,1 ; 1,1)(1,1,1,1 ; 1,1)$ \\
\hline $\begin{array}{l}\text { If factor has one of the } \\
\text { above linguistic variables }\end{array}$ & Reciprocals of above \\
\hline
\end{tabular}


Source: (Kahraman et al., 2014).

\begin{tabular}{|l|l|}
\hline assigned to it when & \\
compared with factor $j$, then & \\
$j$ has the reciprocal value & \\
when compared with $i$ & \\
\hline
\end{tabular}

Step 2. The consistency of each fuzzy pairwise comparison matrix is examined. Assume $A=\left[a_{i j}\right]$ is a positive reciprocal matrix and $\tilde{\tilde{A}}=\left[\tilde{\tilde{a}}_{i j}\right]$ is a fuzzy positive reciprocal matrix. If the result of the comparisons of $A=\left[a_{i j}\right]$ is consistent, then it can imply that the result of the comparisons of $\tilde{\tilde{A}}=\left[\tilde{\tilde{a}}_{i j}\right]$ is also consistent. In order to check the consistency of the fuzzy pairwise comparison matrices, the defuzzified method DTraT which is given by Eq. 1 is used.

Step 3. The geometric mean of each row is calculated and then the fuzzy weights are computed by normalization. The geometric mean of each row $\tilde{\tilde{r}}_{i}$ is calculated as

$$
\tilde{\tilde{r}}_{i}=\left[\tilde{\tilde{a}}_{i 1} \otimes \tilde{\tilde{a}}_{i 2} \otimes \cdots \otimes \tilde{\tilde{a}}_{i n}\right]^{1 / n}
$$

where

$$
\sqrt[n]{\tilde{\tilde{a}}_{i j}}=\left(\left(\sqrt[n]{a_{i j 1}^{U}}, \sqrt[n]{a_{i j 2}^{U}}, \sqrt[n]{a_{i j 3}^{U}}, \sqrt[n]{a_{i j 4}^{U}} ; H_{1}^{U}\left(a_{i j}\right), H_{2}^{U}\left(a_{i j}\right)\right),\left(\sqrt[n]{a_{i j 1}^{L}}, \sqrt[n]{a_{i j 2}^{L}}, \sqrt[n]{a_{i j 3}^{L}}, \sqrt[n]{a_{i j 4}^{L}} ; H_{1}^{L}\left(a_{i j}\right), H_{2}^{L}\left(a_{i j}\right)\right)\right) .
$$

The fuzzy weight of the $i$ th criterion is calculated as

$$
\tilde{\tilde{w}}_{i}=\tilde{\tilde{r}}_{i} \otimes\left[\tilde{\tilde{r}}_{1} \oplus \ldots \oplus \tilde{\tilde{r}}_{i} \oplus \ldots \oplus \tilde{\tilde{r}}_{n}\right]^{-1}
$$

where the power $(-1)$ represents the reciprocal of the corresponding trapezoidal interval type-2 fuzzy set.

Step 4. The fuzzy weights and fuzzy performance scores are aggregated as follows:

$$
\tilde{\tilde{U}}_{i}=\sum_{j=1}^{n}\left(\tilde{\tilde{w}}_{j} \otimes \tilde{\tilde{r}}_{i j}\right)
$$

where $\tilde{\tilde{U}}_{i}$ is the fuzzy utility of alternative $i$; $\tilde{\tilde{w}}_{j}$ is the weight of the criterion $j$, and $\tilde{\tilde{r}}_{i j}$ is the performance score of alternative $i$ with respect to criterion $j$.

Step 5. Defuzzify the fuzzy utility of alternatives by using DTraT and normalize these values to determine the best alternative.

\section{An application on portfolio selection problem}

The Portfolio Selection problem is a multi-criteria decision making problem and is inherently uncertain. In this section, we will first present the financial ratios for the evaluation of alternative stocks.

In order to demonstrate the applicability of our methodology in this part of our study, 5 stock selected from Borsa İstanbul by using the past price movements. In order to evaluate our alternative stocks, we selected five important financial ratios as follows:

C1: Market to book value ratio: The book-to-market ratio is used to find a company's value by comparing its book value to its market value. A company's book value is calculated by looking 
at the company's historical cost, or accounting value (Retrieved from https://www.investopedia.com/terms/b/booktomarketratio.asp).

C2: Net profit margin: The net profit margin is equal to how much net income or profit is generated as a percentage of revenue. Net profit margin is the ratio of net profits to revenues for a company or business segment. The net profit margin illustrates how much of each dollar in revenue collected by a company translates into profit (Retrieved from https://www.investopedia.com/terms/n/net_margin.asp).

C3: Return on capital employed (ROCE): Return on capital employed (ROCE) is a financial ratio that measures a company's profitability and the efficiency with which its capital is used. In other words, the ratio measures how well a company is generating profits from its capital (Retrieved from https://www.investopedia.com/terms/r/roce.asp).

C4: Return on assets (ROA): Return on assets is a profitability ratio that provides how much profit a company is able to generate from its assets. In other words, return on assets (ROA) measures how efficient a company's management is in generating earnings from their economic resources or assets on their balance sheet (Retrieved from https://www.investopedia.com/ask/answers/031215/what-formula-calculating-return-assetsroa.asp).

C5: Price-to-Earnings Ratio (P/E Ratio): The price-to-earnings ratio (P/E ratio) is the ratio for valuing a company that measures its current share price relative to its per-share earnings (EPS) (Retrieved from https://www.investopedia.com/terms/p/price-earningsratio.asp).

And we obtained C1: Market to book value ratio, C2: Net profit margin, C3: Return on capital employed (ROCE), C4: Return on assets (ROA), C5: Price-to-Earnings Ratio (P/E Ratio) financial ratio values from the website of finnet.com.tr on the date of 01.02.2019 for each selected alternative stocks. Our decision maker who provided these values filled the evaluation matrices. After this stage, we apply the steps of the proposed interval type- 2 fuzzy AHP method in the following.

Step 1. Table 2 and Table 3-7 present pairwise comparison matrices for criteria and alternatives using linguistic terms, respectively. Then, fuzzy pairwise comparison matrices are constructed by using the interval type 2 fuzzy scales of the linguistic variables in Table 1.

Table 2: Pairwise comparison matrix for criteria.

\begin{tabular}{|c|c|c|c|c|c|}
\hline & $\mathrm{C} 1$ & $\mathrm{C} 2$ & $\mathrm{C} 3$ & $\mathrm{C} 4$ & $\mathrm{C} 5$ \\
\hline $\mathrm{C} 1$ & $\mathrm{E}$ & $\mathrm{SS}$ & $\mathrm{FS}$ & $\mathrm{VS}$ & $\mathrm{AS}$ \\
\hline $\mathrm{C} 2$ & $1 / \mathrm{SS}$ & $\mathrm{E}$ & $\mathrm{SS}$ & $\mathrm{SS}$ & $\mathrm{VS}$ \\
\hline $\mathrm{C} 3$ & $1 / \mathrm{FS}$ & $1 / \mathrm{SS}$ & $\mathrm{E}$ & $\mathrm{SS}$ & $\mathrm{SS}$ \\
\hline $\mathrm{C} 4$ & $1 / \mathrm{VS}$ & $1 / \mathrm{SS}$ & $1 / \mathrm{SS}$ & $\mathrm{E}$ & $\mathrm{SS}$ \\
\hline $\mathrm{C} 5$ & $1 / \mathrm{AS}$ & $1 / \mathrm{VS}$ & $1 / \mathrm{SS}$ & $1 / \mathrm{SS}$ & $\mathrm{E}$ \\
\hline
\end{tabular}

Table 3: Pairwise comparison matrix for alternatives w.r.t. C1.

\begin{tabular}{|c|c|c|c|c|c|}
\hline & A1 & A2 & A3 & A4 & A5 \\
\hline A1 & E & FS & AS & SS & VS \\
\hline A2 & $1 / \mathrm{FS}$ & E & FS & $1 / \mathrm{SS}$ & SS \\
\hline A3 & $1 / \mathrm{AS}$ & $1 / \mathrm{FS}$ & $\mathrm{E}$ & $1 / \mathrm{VS}$ & $1 / \mathrm{SS}$ \\
\hline A4 & $1 / \mathrm{SS}$ & $\mathrm{SS}$ & $\mathrm{VS}$ & $\mathrm{E}$ & $\mathrm{FS}$ \\
\hline A5 & $1 / \mathrm{VS}$ & $1 / \mathrm{SS}$ & $\mathrm{SS}$ & $1 / \mathrm{FS}$ & $\mathrm{E}$ \\
\hline
\end{tabular}

Table 4: Pairwise comparison matrix for alternatives w.r.t. C2. 


\begin{tabular}{|c|c|c|c|c|c|}
\hline & A1 & A2 & A3 & A4 & A5 \\
\hline A1 & E & SS & VS & AS & FS \\
\hline A2 & $1 / \mathrm{SS}$ & E & FS & VS & SS \\
\hline A3 & $1 / \mathrm{VS}$ & $1 / \mathrm{FS}$ & $\mathrm{E}$ & $\mathrm{SS}$ & $1 / \mathrm{SS}$ \\
\hline A4 & $1 / \mathrm{AS}$ & $1 / \mathrm{VS}$ & $1 / \mathrm{SS}$ & $\mathrm{E}$ & $1 / \mathrm{FS}$ \\
\hline
\end{tabular}

Table 5: Pairwise comparison matrix for alternatives w.r.t. C3.

\begin{tabular}{|c|c|c|c|c|c|}
\hline & A1 & A2 & A3 & A4 & A5 \\
\hline A1 & E & SS & FS & AS & VS \\
\hline A2 & $1 / \mathrm{SS}$ & E & SS & VS & VS \\
\hline A3 & $1 / \mathrm{FS}$ & $1 / \mathrm{SS}$ & $\mathrm{E}$ & $\mathrm{FS}$ & $\mathrm{SS}$ \\
\hline A4 & $1 / \mathrm{AS}$ & $1 / \mathrm{VS}$ & $1 / \mathrm{FS}$ & $\mathrm{E}$ & $1 / \mathrm{SS}$ \\
\hline A5 & $1 / \mathrm{VS}$ & $1 / \mathrm{VS}$ & $1 / \mathrm{SS}$ & $\mathrm{SS}$ & $\mathrm{E}$ \\
\hline
\end{tabular}

Table 6: Pairwise comparison matrix for alternatives w.r.t. C4.

\begin{tabular}{|c|c|c|c|c|c|}
\hline & A1 & A2 & A3 & A4 & A5 \\
\hline A1 & E & SS & FS & AS & SS \\
\hline A2 & $1 / \mathrm{SS}$ & E & VS & VS & SS \\
\hline A3 & $1 / \mathrm{FS}$ & $1 / \mathrm{VS}$ & E & SS & $1 / \mathrm{SS}$ \\
\hline A4 & $1 / \mathrm{AS}$ & $1 / \mathrm{VS}$ & $1 / \mathrm{SS}$ & $\mathrm{E}$ & $1 / \mathrm{FS}$ \\
\hline A5 & $1 / \mathrm{SS}$ & $1 / \mathrm{SS}$ & $\mathrm{SS}$ & $\mathrm{FS}$ & $\mathrm{E}$ \\
\hline
\end{tabular}

Table 7: Pairwise comparison matrix for alternatives w.r.t. C5.

\begin{tabular}{|c|c|c|c|c|c|}
\hline & A1 & A2 & A3 & A4 & A5 \\
\hline A1 & E & $1 / \mathrm{SS}$ & $1 / \mathrm{FS}$ & FS & SS \\
\hline A2 & SS & E & $1 / \mathrm{SS}$ & VS & FS \\
\hline A3 & FS & SS & E & AS & VS \\
\hline A4 & $1 / \mathrm{FS}$ & $1 / \mathrm{VS}$ & $1 / \mathrm{AS}$ & $\mathrm{E}$ & $1 / \mathrm{SS}$ \\
\hline A5 & $1 / \mathrm{SS}$ & $1 / \mathrm{FS}$ & $1 / \mathrm{VS}$ & $\mathrm{SS}$ & $\mathrm{E}$ \\
\hline
\end{tabular}

Step 2. Using the DTraT method, the defuzzified matrices are obtained. All defuzzified matrices have been checked for its consistency that is the consistency ratio of each matrix has been found under 0.1 .

Step 3. Geometric mean of each row of comparison matrices is calculated by using Eq. 2. For the representative calculations, Table 3 is used, which includes the type- 2 fuzzy sets of pairwise comparisons of alternatives with respect to $\mathrm{C} 1$. For example the geometric mean of the first row is calculated as:

$$
\begin{gathered}
\tilde{\tilde{r}}_{1}=\left[\tilde{\tilde{a}}_{11} \otimes \tilde{\tilde{a}}_{12} \otimes \tilde{\tilde{a}}_{13} \otimes \tilde{\tilde{a}}_{14} \otimes \tilde{\tilde{a}}_{15}\right]^{1 / 5}=[(1,1,1,1 ; 1,1)(1,1,1,1 ; 1,1) \otimes(3,4,6,7 ; 1,1)(3.2,4.2,5.8,6.8 ; 0.8,0.8) \otimes \\
(7,8,9,9 ; 1,1)(7.2,8.2,8.8,9 ; 0.8,0.8) \otimes(1,2,4,5 ; 1,1)(1.2,2.2,3.8,4.8 ; 0.8,0.8) \otimes(5,6,8,9 ; 1,1) \\
(5.2,6.2,7.8,8.8 ; 0.8,0.8)]^{1 / 5}=(2.54,3.29,4.44,4.90 ; 1,1)(2.70,3.42,4.33,4.81 ; 0.8,0.8)
\end{gathered}
$$

The geometric mean of the remaining rows of Table 3 are given in Table 8 .

Table 8: Geometric means $\tilde{\tilde{r}}_{i}$ of pairwise comparison matrix for alternatives w.r.t. Cl. 


\begin{tabular}{|l|c|}
\hline A1 & $(2.54,3.29,4.44,4.90 ; 1,1)(2.70,3.42,4.33,4.81 ; 0.8,0.8)$ \\
\hline A2 & $(0.61,0.80,1.25,1.64 ; 1,1)(0.65,0.84,1.19,1.53 ; 0.8,0.8)$ \\
\hline A3 & $(0.20,0.23,0.30,0.39 ; 1,1)(0.21,0.23,0.29,0.37 ; 0.8,0.8)$ \\
\hline A4 & $(1.25,1.64,2.49,3.16 ; 1,1)(1.33,1.72,2.39,2.99 ; 0.8,0.8)$ \\
\hline A5 & $(0.32,0.40,0.61,0.80 ; 1,1)(0.33,0.42,0.58,0.75 ; 0.8,0.8)$ \\
\hline
\end{tabular}

The priority weights of criteria and alternatives are determined by using Eq. 3. For example the priority weights of alternatives w.r.t. $\mathrm{C} 1$ can be calculated as follows:

$\tilde{\tilde{w}}_{1}=\tilde{\tilde{r}}_{1} \otimes\left[\tilde{\tilde{r}}_{1} \oplus \tilde{\tilde{r}}_{2} \oplus \ldots \oplus \tilde{\tilde{r}}_{5}\right]^{-1}=(2.54,3.29,4.44,4.90 ; 1,1)(2.70,3.42,4.33,4.81 ; 0.8,0.8) \otimes$

$[(2.54,3.29,4.44,4.90 ; 1,1)(2.70,3.42,4.33,4.81 ; 0.8,0.8) \oplus(0.61,0.80,1.25,1.64 ; 1,1)$

$(0.65,0.84,1.19,1.53 ; 0.8,0.8) \oplus(0.20,0.225,0.30,0.39 ; 1,1)(0.21,0.23,0.29,0.37 ; 0.8,0.8)$

$\oplus(1.25,1.64,2.49,3.159 ; 1,1)(1.33,1.72,2.39,2.99 ; 0.8,0.8) \oplus(0.316,0.40,0.608,0.80 ; 1,1)$

$(0.33,0.42,0.58,0.75 ; 0.8,0.8)]^{-1}=(0.23,0.36,0.70,1 ; 1,1)(0.26,0.39,0.65,0.92 ; 0.8,0.8)$.

Normalized geometric means of the pairwise comparison matrices are given in Table 9.

Table 9- Type 2 fuzzy weights of the criteria and alternatives. ---- Priority weights

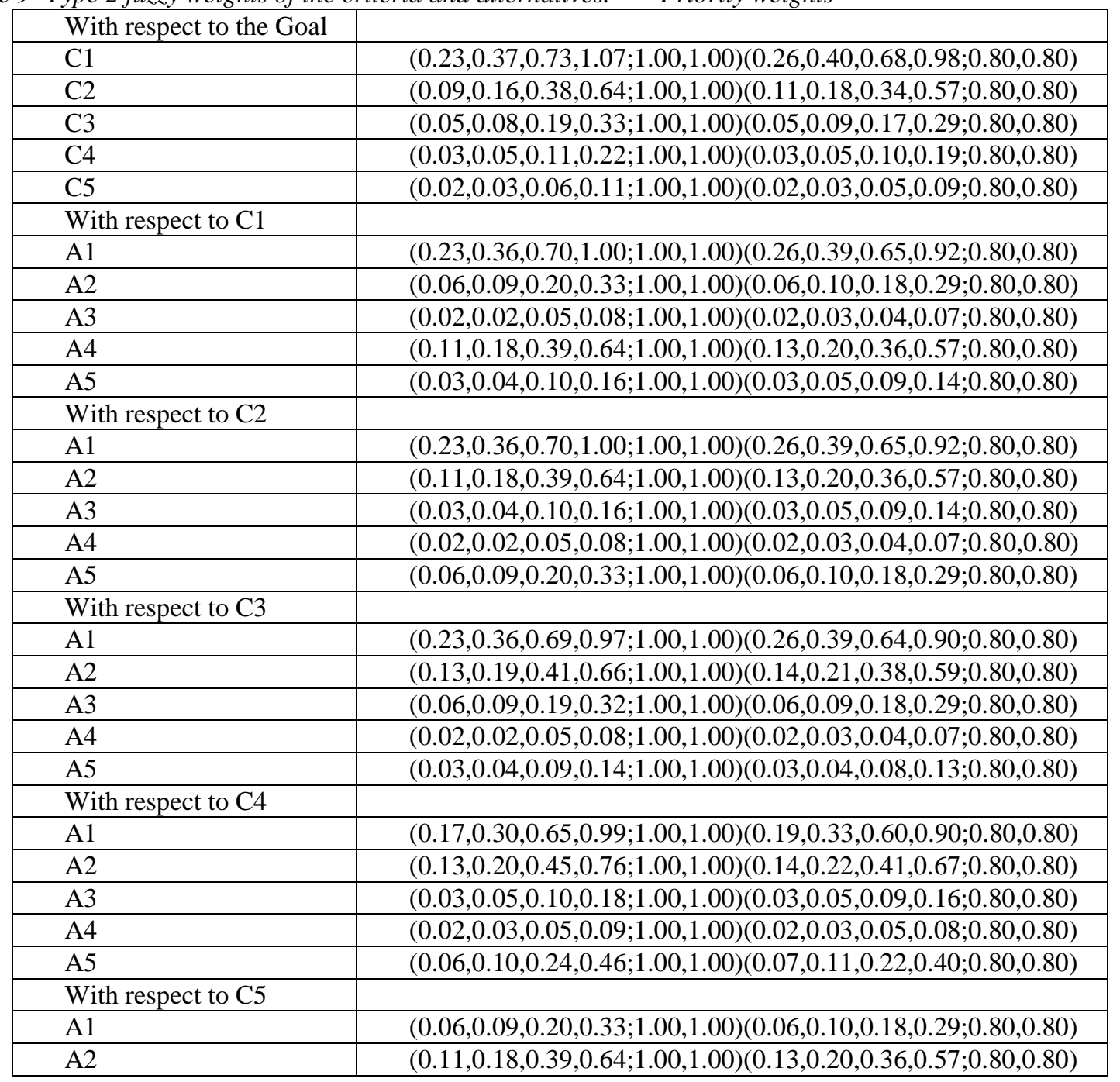




\begin{tabular}{|l|l|}
\hline A3 & $(0.23,0.36,0.70,1.00 ; 1.00,1.00)(0.26,0.39,0.65,0.92 ; 0.80,0.80)$ \\
\hline A4 & $(0.02,0.02,0.05,0.08 ; 1.00,1.00)(0.02,0.03,0.04,0.07 ; 0.80,0.80)$ \\
\hline A5 & $(0.03,0.04,0.10,0.16 ; 1.00,1.00)(0.03,0.05,0.09,0.14 ; 0.80,0.80)$ \\
\hline
\end{tabular}

Step 4. The fuzzy weights and fuzzy performance scores are aggregated by (4) and the results are given in Table 10.

Table 1- U Vector

\begin{tabular}{|c|c|c|c|}
\hline & $\tilde{\tilde{U}}_{i}$ & $\begin{array}{c}\text { Defuzzified } \\
\text { values }\end{array}$ & $\begin{array}{c}\text { Normalized } \\
\text { Values }\end{array}$ \\
\hline A1 & $(0.13,0.20,0.44,0.80 ; 1.00,1.00)(0.15,0.21,0.40,0.69 ; 0.80,0.80)$ & 0.36 & 0.14 \\
\hline A2 & $(0.27,0.40,0.87,1.55 ; 1.00,1.00)(0.30,0.43,0.79,1.35 ; 0.80,0.80)$ & 0.72 & 0.28 \\
\hline A3 & $(0.55,0.80,1.55,2.41 ; 1.00,1.00)(0.60,0.86,1.44,2.17 ; 0.80,0.80)$ & 1.24 & 0.48 \\
\hline A4 & $(0.04,0.05,0.11,0.19 ; 1.00,1.00)(0.05,0.06,0.10,0.17 ; 0.80,0.80)$ & 0.09 & 0.04 \\
\hline A5 & $(0.07,0.10,0.21,0.39 ; 1.00,1.00)(0.07,0.11,0.19,0.34 ; 0.80,0.80)$ & 0.18 & 0.07 \\
\hline
\end{tabular}

Step 5. By using DTraT, the fuzzy utility of alternatives are defuzzified and then normalized ans the results are given in Table 10. Considering the normalized values, the solution states that the investor should allocate his/her fund in ratios of $48 \%, 28 \%, 14 \%, 7 \%, 4 \%$ to A3, A2, A1, A5 and A4, respectively.

\section{Conclusion}

In this study, the portfolio selection problem, which is included in the scope of finance theory and which is examined very widely, is discussed. There are methods that can be used effectively in the current financial literature for portfolio selection. However, as is known, the methods that reflect the uncertainty arising from the future in the best way to the model are evaluated and preferred effectively. The movement of stocks in stock exchanges cannot be known in advance. However, past price movements give insight about shares. From this point of view, it is clear that the approaches that make evaluation in terms of portfolio in the fuzzy environment according to financial ratios and which are preferred among alternatives. Within the scope of our paper, the main objective was to rank a set of stocks in a fuzzy environment and thus to demonstrate the usefulness of fuzzy methodology in financial problems. The ranking or preference numbers serve as a guide to how to allocate the available monetary resources among the given stocks. Here this is accomplished by interval Type-2 fuzzy Ahp which is proposed by (Kahraman et al., 2014).

\section{Acknowledgment}

This research has been supported by Yildiz Technical University Scientific Research Projects Coordination Department. Project Number: FBA-2017-3073.

\section{References}

[1] Alexander, G. J., Sharpe, W. F., \& Bailey, J. V. (2003). Fundamentals of investments/fundamentos de inversiones. Pearson Educación.

[2] Bhattacharyya, R., Kar, S., \& Majumder, D. D. (2011). Fuzzy mean-variance-skewness portfolio selection models by interval analysis. Computers \& Mathematics with Applications, 61(1), 126-137. 
[3] Bilbao-Terol, A., Pérez-Gladish, B., Arenas-Parra, M., \& Rodríguez-Uría, M. V. (2006). Fuzzy compromise programming for portfolio selection. Applied Mathematics and computation, 173(1), 251-264.

[4] Boender, C. G. E., De Graan, J. G., \& Lootsma, F. A. (1989). Multi-criteria decision analysis with fuzzy pairwise comparisons. Fuzzy sets and Systems, 29(2), 133-143.

[5] Buckley, J. J. (1985). Fuzzy hierarchical analysis. Fuzzy sets and systems, 17(3), 233-247.

[6] Chang, D. Y. (1996). Applications of the extent analysis method on fuzzy AHP. European journal of operational research, 95(3), 649-655.

[7] Chen, M. F., Tzeng, G. H., \& Ding, C. G. (2008). Combining fuzzy AHP with MDS in identifying the preference similarity of alternatives. Applied Soft Computing, 8(1), 110-117.

[8] Giove, S., Funari, S., \& Nardelli, C. (2006). An interval portfolio selection problem based on regret function. European Journal of Operational Research, 170(1), 253-264.

[9] Huang, J. J., Tzeng, G. H., \& Ong, C. S. (2006). A novel algorithm for uncertain portfolio selection. Applied Mathematics and computation, 173(1), 350-359.

[10] Inuiguchi, M., \& Tanino, T. (2000). Portfolio selection under independent possibilistic information. Fuzzy sets and systems, 115(1), 83-92.

[11] Kahraman, C., Öztayşi, B., Sarı, İ. U., \& Turanoğlu, E. (2014). Fuzzy analytic hierarchy process with interval type-2 fuzzy sets. Knowledge-Based Systems, 59, 48-57.

[12] Lacagnina, V., \& Pecorella, A. (2006). A stochastic soft constraints fuzzy model for a portfolio selection problem. Fuzzy sets and systems, 157(10), 1317-1327.

[13] Li, X., Qin, Z., \& Kar, S. (2010). Mean-variance-skewness model for portfolio selection with fuzzy returns. European Journal of Operational Research, 202(1), 239-247.

[14] Li, X., Guo, S., \& Yu, L. (2015). Skewness of fuzzy numbers and its applications in portfolio selection. IEEE Transactions on Fuzzy Systems, 23(6), 2135-2143.

[15] Markowitz, H. M. (1952). Portfolio Selection/Harry Markowitz. The Journal of Finance, 7(1), 77-91.

[16] Ong, C. S., Huang, J. J., \& Tzeng, G. H. (2005). A novel hybrid model for portfolio selection. Applied Mathematics and computation, 169(2), 1195-1210.

[17] Parra, M. A., Terol, A. B., \& Urıa, M. R. (2001). A fuzzy goal programming approach to portfolio selection. European Journal of Operational Research, 133(2), 287-297.

[18] Tanaka, H., \& Guo, P. (1999). Portfolio selection based on upper and lower exponential possibility distributions. European Journal of operational research, 114(1), 115-126.

[19] Tanaka, H., Guo, P., \& Türksen, I. B. (2000). Portfolio selection based on fuzzy probabilities and possibility distributions. Fuzzy sets and systems, 111(3), 387-397.

[20] Tiryaki, F. (2001). The use of data envelopment analysis for stocks selection on Istanbul stock exchange. In PICMET'01. Portland International Conference on Management of Engineering and Technology. Proceedings Vol. 1: Book of Summaries (IEEE Cat. No. 01CH37199) (Vol. 1, pp. 373-vol). IEEE.

[21] Tiryaki, F., \& Ahlatcioglu, M. (2005). Fuzzy stock selection using a new fuzzy ranking and weighting algorithm. Applied Mathematics and Computation, 170(1), 144-157. 
[22] Tiryaki, F., \& Ahlatcioglu, B. (2009). Fuzzy portfolio selection using fuzzy analytic hierarchy process. Information Sciences, 179(1-2), 53-69.

[23] Saaty, T. L. (1980). The Analytic Hierarchy Process McGraw-Hill New York. AGRICULTURAL ECONOMICS REVIEW, 70.

[24] Van Laarhoven, P. J., \& Pedrycz, W. (1983). A fuzzy extension of Saaty's priority theory. Fuzzy sets and Systems, 11(1-3), 229-241.

[25] Xia, Y., Liu, B., Wang, S., \& Lai, K. K. (2000). A model for portfolio selection with order of expected returns. Computers \& Operations Research, 27(5), 409-422.

[26] Zadeh, L. A. (1965). Fuzzy sets. Information and control, 8(3), 338-353.

[27] Zhang, W. G., Wang, Y. L., Chen, Z. P., \& Nie, Z. K. (2007). Possibilistic mean-variance models and efficient frontiers for portfolio selection problem. Information Sciences, 177(13), 2787-2801.

[28] Zhou, X., Wang, J., Yang, X., Lev, B., Tu, Y., \& Wang, S. (2018). Portfolio selection under different attitudes in fuzzy environment. Information Sciences, 462, 278-289. 